\title{
Inter Relationship between Team Conflict Management, Employee Satisfaction and Organizational Performance
}

\author{
Asif Mehmood Rana1*, Faiz Ahmed², Dr.Kashif-ur-Rehman ${ }^{1}$ \\ 1Iqra University Islamabad, Pakistan \\ 2Department of Management Sciences FUUAST, Islamabad, Pakistan \\ *abyan_asif@hotmail.com
}

\begin{abstract}
Team work in competitive environment has attained greater Importance for organizations to enhance their performance. This paper is described the team conflict management with its antecedence like trust, task interdependence and managerial coping skill, whereas dependent variables i.e. team conflict management styles, employees satisfaction and organizational performance has been chosen as outcomes. To evaluate the deduction of other studies have been made part of this paper. This paper is conceptual in nature henceforth, relations between independently and dependent variables have been described. Studies proved that there is a strong relation between team conflict management with employee's satisfaction and organizational Performance. It is recommended that to Executives, Managers Trust and Task interdependence between the team members have positive impact on TCMS (Team conflict management styles). Present paper provides the solution to handle the conflicts within the team and with the team. Future research is directed for its empirical testing of TCMS model" should be replaced with sound implication.
\end{abstract}

Keywords: Team conflict, trust, culture task interdependence, organizational performance

\section{Introduction}

Team work is the requirement of this era to achieve organizational goals, when peoples have been working together then conflicts also arises, which is the natural part of life. Team members spend most of their time in the workplace handling with conflicts (Morris et al., 1998). In a team, there are many people and everyone having their own behavior sometime these behaviors causes the interpersonal conflicts, which can be demolish the team relationships and effect the performance of the team (West, 2004).How we can manage the team conflicts creatively rather than destroy relationships? We should train people to manage their conflicts in a constructive way (Karp, 1983).In view of conflicts on work place has affected commonly all team members. The success of every member promotes the positive relation to all participant success .In that case, they managed their conflict mutually and personal interaction, support and eliminate the tendency of conflict among the team members. Conflict endures in a team till continued at identification of specific disputes among the team members, individual play important role for recognition of conflict (Neal, Mannix \& Griffith, 2003). Trust element usually developed due to more mutual and personal interaction and positive response from each member commitment for the benefits to other (Lee-Kelley \& Crossman, 2011).The purpose of this study is examining the role of trust and task interdependence. To establish effective team relation in the presence of various conflicts areas, to manage the issues in productive way. Team effectiveness and strong team foundation has based on trust and managerial skills.

Cooperative teams basically develop for completion of work in effective team's plan that take diverse talents and join them in a one unit. Thus, members have shared their problems with the team member and develop a strong communication network for smooth working to achieve the challenging goals. Cooperation or collaboration is called the "win/win" approach. Where everybody is win and nobody is not in loose. When we apply cooperative approach in a team members resolve the conflicts and encourage the people to bring the solutions. Team member develop a constructive approach to resolve the issues before emerging the problems within team (Karp, 2012). Cooperative style gives importance to the own interest and the other team members interest as well, it is called a win and win approach, but in the competitive style own interest is more important than the other members which is called as win and lose approach (Rahim, 2001). This study emphasis that how conflict can be managed with the collective efforts of team members, the cooperation like sharing of expertise and skills and developing the trust environment, where everyone feel comfortable. To develop the trust and encouraging the 
constructive conflict rather than destructive, whether it is cooperative or competitive. Which type style will affective it's up to team to adopt it depend up the nature of work and requirement of particular task (Klein, 2000). Present study has its important to provide the professional approach to resolve the team conflicts in emerging issues face by multinational companies operate in Pakistan especially in banking and telecom sector.

\section{Conceptual Background and Hypothesis:}

Team: In new era organizations, teams build the way of choice for responding quickly with technology and market changes for the purpose of organization's probability of continued existence in the industry (Illgen, Hollenbeck, Jhnson \& Jundt, 2006; Richter, West, van Dick, \& Dawson, 2006). Efficient teams develop with significant research and motivated human efforts have been examined the correct creation of teams (e.g. Illgen et al., 2006).In addition, research has exposed, how a conflict affects the teams and team members manage their conflicts, sometime conflict has revealed productive and negative impact on the team(Ayoko, Hartel \& Cullen, 2002; De Dreu \& van de Vliert, 1997). A number of studies have not shown the main team characteristics and tendency of a conflict that affect team members, choice for the pattern of conflict management style.

\section{Figure 1: Conceptual Model of TCMS}

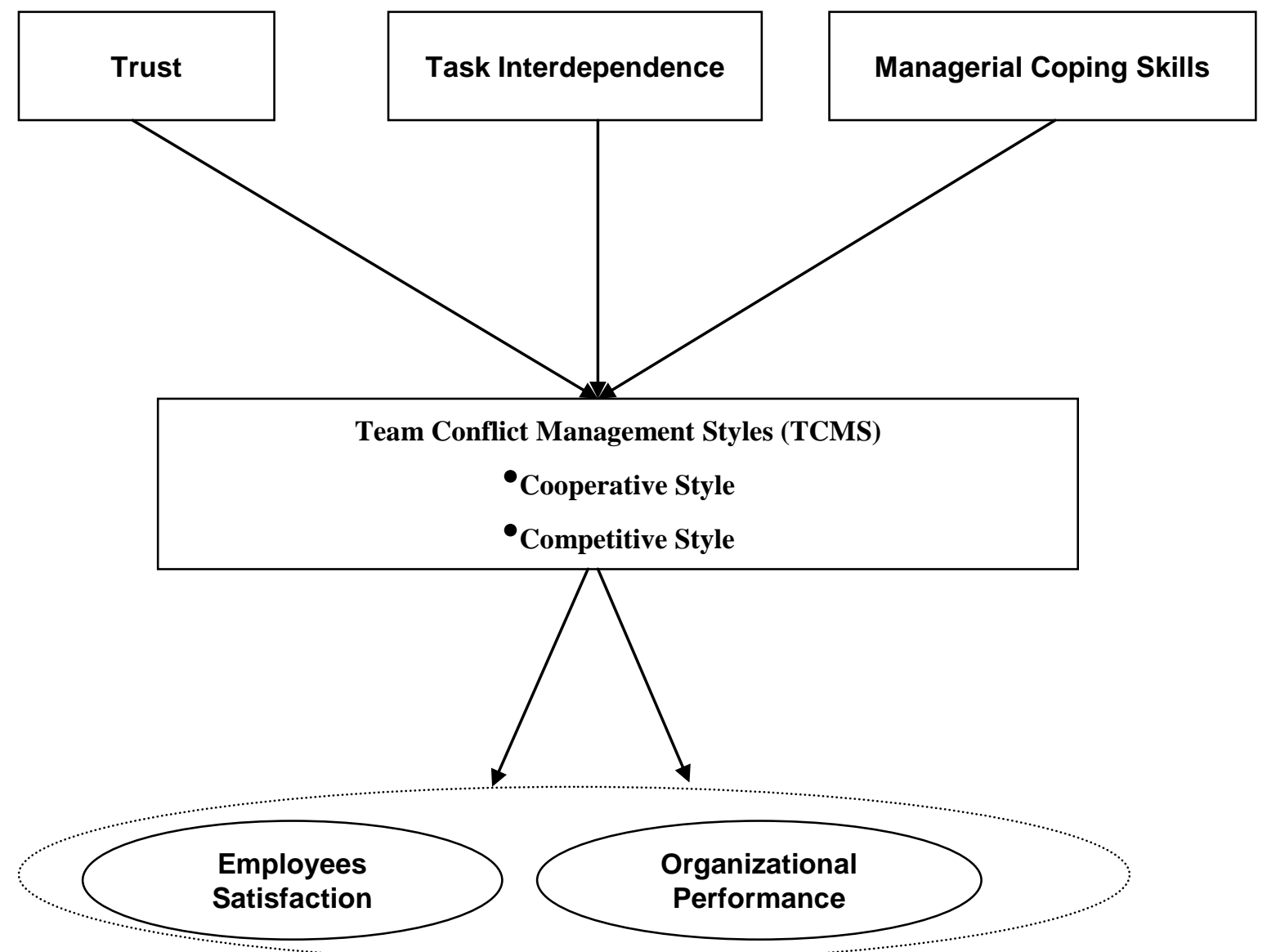

Team Conflict Management Styles: Conflict Management patterns established during the interaction of team members and long term relationship among the team members and difference of opinion among the team members (Kuhn \& Poole, 2000). In the previous study we find Team identity among the task interdependence and both style of conflict management it was shown as the intervening variable but we ensure that team identity is itself exist in both styles (cooperative conflict Management style and competitive conflict management style). Conflict-management styles have generally been predict the members attributes and characteristics whose perform these values and tendencies individual bases in the teams in connection with that studies researcher defined the different pattern of team conflict management styles (Kuhen et al., 2000). Jehn (1997) investigate the member has shown commonly willing norms and values in the conflict and openly responded against the problem and the settlements of 
the issues and pointed out the individual feeling among the group members . Group members approach influential way of common thinking against the issues and how to eliminate the factors of disagreements (Ehrhart \& Nauman, 2004). Conflict should be resolve in the initial stage otherwise it can be cause of greater loss which will influence the overall organization performance in the later stage. Team members should resolve their conflicts on one to one basis when problem initially arise. (Michael West, 2004).

Cooperative Conflict Management Styles and Competitive Conflict Management Styles: Cooperative and competitive conflict management patterns are strongly accept able styles in conflict appealing area of conflict management styles. If group members have common objective and same direction of efforts to achievement their goals and resultantly a strong and effective team build (Law \& Tjosvold, 2000).The competitive style refer to closely related to other and extensively integrated to self engage and as well a challenging ,controlling ,opposing (Rahim et al., 2001). Cooperative styles gives respects and importance to others, therefore manager uses this conflict management style to win trust from their subordinates by which he can achieve desired outcomes. In cooperative conflict management style team follow the integrating obligating and compromising attitude. Cooperative conflict management can help team members to win the confidence that their fellows are reliable and trustworthy (Zhang, Hempel, \& Tjosvold, 2009).

Cooperative style focused on logical dispute, facts and clarification, encourages team members observed the different opinion on the bases of knowledge and find out the reliable alternatives to resolved them. In reverse, competitive style proceed to set on disputes by self made theory on gain and other member away from success (Yetton \& Bottger, 1988) .On the whole, the practical literature shown that a positive team out come regarding to cooperative conflict management approach and competitive conflict management approach repeatedly effect in conflict appreciation and reflect negative out comes (Alper et al., 2000).This study adds a great value on conflict management style with trust, task interdependence and managerial copying skill as well as outcomes; employee satisfaction and organizational performance.

Trust: Even though the focus of this research is on the trust that has paying attention toward individual social and organization norms, values and behavior, individual contribution mostly relate to the commitment of team member lead to the performance of organization and team outcomes (Seung-hee, Xiaojing, \& Magjuka, 2008). If team members have various ideas in complex situation, that can help to enhance the team effectiveness and resolved the issues between team members (Pirola et al., 2004). Mostly studies recommend that some individual characteristics, personal attributes or hostility are related with trust (Rodgers, Scott Poole \& Brown, 2004).The study measure the trust factor within the team and between the team, how the level of trust impacts positively on the organizational performance and employee's satisfaction. Trust brings the positive conduct with the other team member and builds the relationship for achievement of the defined goals (Camerer, Sitkin, Burt \& Rousseau, 1998). In the presence of trust team members performs their tasks smoothly, affectively, and economically which reduce the cost and time factor and to get the desired outcomes with the help of sharing knowledge ideas (Grant and Baden-Fuller, 2004).

\section{H1: Trust has significant impact on team Conflict Management Styles.}

Task Interdependence: Mostly study examined that team performance highly admired and collaborative as compare to individual performance, members are strongly connected to exchange the new ideas for resolving the issues among the team members, creativity and effectiveness of team process impact the valuable team outcomes, in absence of trust has established to reverse impact on team member's interest of work to attachment of each member in team process and member's contentment (Kiffin-Pettersen, 2004). In view of present study trust is integrated with constant and communication and continual interpersonal interaction to build the loyalty and willing to the work with team members (McEvily, Wilson \& Straus, 2006). Mostly Researchers suggested that if task interdependence has exist in organizational structure or different nature of departments, mutually dependent structure provide the better coordination among the team members who will be working in different department and perform various task in a deliberate arrangement of any organization (Byrd \& Brown, 2003; Gillespie \& Mann, 2004). Particularly, the sense of responsibility among the members enhanced the organization efficiency due to inter related task and supporting activities.

H2: Task Interdependent has the significant impact on team conflict management styles. 
Managerial Copying Skills: This study emphasis about the managerial copying skills and effective training system which play a vital part of organization support, like cross functional nature of work, team members need a diverse range of skills. Where skills are lacking, management can offer a suitable training courses, workshops, seminars, mentoring programs (whereby more senior or experiences members provide training and guidance to less experienced colleagues (West, 2004). This study aim is how senior management play vital role by copying situation where there is the possibilities arising the conflict. "Coping is vibrant method in which a person rely various kind of skills at different times and manage the circumstances" (Lazarus \& Folkman, 1984).Experience members having the expertise and they cope the situation easily and to organize their work in a structure way, and give importance to the priorities so that the workload between the team members become controllable and that thing reduce stress as compare to the less experienced members they exhausted themselves more easily than the experienced members because un experience members need more cooperation from their teammates (Nurmi 2010). In that situation if the team will be the mixture of both experienced and less experienced members' task can be handling easily with the combine efforts of all team members.

\section{H3: Managerial copying skills have the significant impact on team conflict management styles.}

A psychological and socially characteristics of a team precede the valuable team integration and effective outcomes in a form of employee satisfaction and organizational performance (Somech \& Lidgoster, 2010). A psychological and socially characteristics of a team's precede the valuable team integration and effective outcomes (Syna, Somech, Helena \& Lidgoster, 2009). Suppose if a department developed an effective team, but it is unable to cooperate with the other teams, it will still failure of the organization. Approach should be the overall success of the organization. Senior management should encourage for the constructive relationship with other team members on a formal and informal basis (West, 2004). This study emphasis the importance of managerial expertise how they cope the conflict with the help of skills, training and experience. Experience members having the expertise and they know how to organize work, which task is necessary and how to handle them this things facilitate the overall time as compare to the less experienced members they exhausted themselves more easily than the experts they need more cooperation from their teammates (Nurmi, 2010). The combination of both experienced and less experienced team member if they work together then organizational goal can easily be achieved. It is the responsibility of the senior management that how they can manage their conflicts cooperatively and share their knowledge with openly and fairly by developing trusting relationship by using their managerial copying skills.

H4: Team conflict management styles have the significant impact on the employee's satisfaction.

H5: Team conflict management styles have the significant impact on the Organizational Performance.

\section{Discussion}

Finally this study defined that how managerial skill improve and developed the interaction between the team members, play effective role to support the conflict management styles both in cooperative conflict management approach and competitive conflict management styles. This is important discovery for a team analysis of conflict management on specific issues the target from personal behavior shown by each member as unit and team, set the valuable mode of behavior in the management system. This research work gives the sound knowledge about the effectiveness of cooperative conflict management styles and competitive conflict management style to enhance the organization performance (Alper et al., 2000). Previous study shows that cooperative conflict management style highly acceptable as compare to competitive conflict management style. Presently these study findings suggest that competitive conflict management style also play important role in management to manage the team according the environment, in a vary situations to effect the overall team performance. Second, study hold up the mediating role of team cooperative conflict management approach with integration of managerial coping skill and effective role of trust and task interdependence to rich the team as well as organization performance .As point out in this fragment, personal perception, previous scholars suggestions and valuable literature indicates where the team conflict management styles used and required according to the Strategies, nature of issues and team tasks, goals and mission, organization preference to adopt the team conflict management styles (Illgen et al .,2006). We recommend that if managerial coping skill enhance through training and development definitely the unit and whole the team task complete job and trust level between the team and within team boosted and also their implication for the team performance. 
Conflict and trust are the interrelated to each other's. Many researchers by using qualitative (Barker, 1994) and longitudinal quantitative methods (Langfred, 2007) have fond that conflict in the team can reduce the trust. Suppose if the subordinate have trust on his supervisor he will not argue to him about the assign task and he will try to complete required task without any delay. Trust is a vast phenomenon which can be examined at the personal level, Organizational level, social level, and international levels (Teng \& Das, 2001). Present research emphasis that how we can create the cooperative culture and manage the conflicts in the organization. If we take the example of a support team, everyone in a team knows that cooperation is mandatory to win a game If a person thinks that I am the superstar, but the superstar cannot win the game alone (Lewis, 2000).By taking competitive approach that how competitive style support our culture. In any type of game there must be a winner and a loser. There is thrill in win and loss approach basically this approach enhance the hard working in the individual level and team level. Suppose if there is no concept of competition between the teams then people will not be motivated towards the achievement of goal. Sometime conflicts are constructive and some time it is destructive. Many researchers have different views about team conflict management styles some support the cooperative styles and few supports competitive styles but mostly study supports the cooperative styles, as per the researchers opinions cooperative styles encourage constructive conflicts and competitive styles can be the cause of destructive conflicts.

Managerial Implications: Increasing efficient ways of managing conflict and improve the performance of organization functions through training and the managerial copying skills in the organization and have a cleared valuable effect on organization performance .As suggested by our concept and findings, managerial teams that focused on mutual move toward to argument appear to be excellent for building valuable use of their collaboration for themselves to achieve the set managerial performance and members train the individual for the particular job requirement and also improve the overall skill of the team .Managerial Copying skill play important role in both styles in competitive conflict management style and cooperative conflict management style but normally highly related where socialize member to take on a supportive approach. Training also create conflict expertise of the team member like the cooperative approach and scored low in conflict management (Tjosvold et al., 2003).Before this study ,a full research suggested to work on a specific line to build the cooperative conflict management skill (Tjosvold,1993).

Much research has been conducted on the cooperative style, now there is need to study about the positive aspects of competitive style in a team which can be constructive. A training program provide opportunity to member to understand to each other without hesitation and share the knowledge and thoughts ,compile the better strategy for performance, They finish protecting their ideas long sufficient to ask each other for more knowledge and point of views, all team members eliminate the disagreement points between them and handle the situation in collective decision making and generate new solution to relevant the conflict areas (Somech et al., 2009; Tjosveld, 1997). Essential proof that managerial skill service as a key instrument provide the energy to excel their skill performing the interdependence tasks into major accomplishment .One of the major managerial skill and practices make energize to each member to perform duty and shown the trust on colleagues and this scenario help the team member for effective decision making .

\section{Conclusion}

In this article, we sought to add the presented literature by using and unambiguous finding in area of managerial skill highly associated team performance, in the light of this study employees trust level build to understand this relationship enhance the organization performance. Our outcome have influences a team behavior to interact each other in certain limit and highly equipped with managerial copying skill. It also define the correct path for the managers to manage the destructive type of conflict with appropriate way to coping the managerial skill such as organizational goals . Conclusion of this study harmonize the past exploration shown strong integration these ideas and areas provide the base foundation for the constructive controversy to inter link the team members in supportive relationship to generate new ideas that endorse team efficiency. Future research is directed for its empirical testing of TCMS model, our conceptual model provides the guide line to the researchers and practitioners with insights about the trust relationship between members to managerial copying skill in any type of conflict. 


\section{References}

Alper, S., Tjosvold, D. \& Law, K. S. (2000). Conflict management, efficacy, and performance in organizational teams. Personnel Psychology, 53, 625-642.

Bain, P. G., Mann, A. \& Pirola-Merlo. (2001). The innovation imperative: The relationship between team climate, innovation, and performance in research and development teams. Small Group Research, 32, 55-73.

Barker, C. (1994). Research Methods in Clinical and Counseling Psychology. Chichester: John Wiley \& Sons.

Byrd, J. \& Brown, P. (2003). The innovation equation: Building creativity and risk-taking in your organization. San Francisco: Jossey-Bass.

Ayoko, O. B., Hartel, C. E. J. \& Cullen, V. J. (2002). Resolving the puzzle of productive and destructive conflict in culturally heterogeneous work groups: A communication accommodation theory approach. International Journal of Conflict Management, 13, 165-187.

De Dreu, C. \& Van de Vliert, E. (1997). Using conflict in organizations. Beverly Hills, CA: Sage.

Ehrhart, M. G. \& Naumann, S. E. (2004). Organizational citizenship behavior in work groups: A group norms approach. Journal of Applied Psychology, 89, 960-974.

Gillespie, N. A. \& Mann, L. (2004). Transformational leadership and shared values: the building blocks of trust. Journal of Managerial Psychology, 19, 588-607.

Grant, R. M. \& Baden-Fuller, C. (2004). A knowledge accessing theory of strategic alliances. J Manage Stud, 41, 61-84.

Griffith, T., Mannix, E. A. \& Neale, M. A. (2003). Conflict in virtual teams. In S. G. Hempei, Zhang.

Illgen, D. R., Hollenbeck, J. R., Johnson, M. \& Jundt, D. (2006). Teams in organizations: From I-P-O models to IMOI models. Annual Review, 56, 517-543.

Jehn, K. A. (1997). A qualitative analysis of conflict types and dimensions in organizational groups. Administrative Science Quarterly, 42, 530-557.

Karp, D. A. (1983). The College Classroom: Some Observations on the Meanings of Student Participation, In Rube, H. and Clark, C. (Eds.), Social Interaction: Reading in Sociology. New York: St. Martin's Press, 195-210.

Karp, D. A. (2012). College 101 courses for application and student success (CCRC Paper). New York, NY: Columbia University, Teachers College, Community College Research Center. Manuscript in preparation.

Kiffin-Petersen, S. A. (2004). Trust: A neglected variable in team effectiveness research. Journal of the Australian and New Zealand Academy of Management, 10(1), 38-53.

Klein, K. J. (2000). A multilevel approach to theory and research in organizations: Contextual, temporal, and emergent processes.

Kuhn, T. \& Poole, M. (2000). Do conflict management styles affect group decision making? Evidence from a longitudinal field study. Human Communication Research, 26, 558-590.

Langfred, C. W. (2007). The downside of self-management: A longitudinal study of the effects of conflict on trust, autonomy, and task independence in self-managing teams. Academy of Management Journal, 50, 885-900.

Lazarus, R. S. \& Folkman, S. (1984). Stress, appraisal, and coping. New York: Springer.

Lee-Kelley. \& Crossman, A. (2011). Trust, commitment and team working: the paradox of virtual organizations. Global Networks, 4(4), 376.

Lee, X. Liu, R. M. (2008). Understanding the dimensions of virtual teams. International Journal of Elearning, 5, 4, 507-52.

Lewis, C. (2000) A Man's Place: Fathers and Families in the UK. York: Joseph Rowntree Foundation.

Morris, M. W., Williams, K. Y., Leung, K., Larrick, R., Mendoza, M. T., Bhatnagar, D., Li, J., Kondo, M., Luo, J. L. and Hu, J. C. (1998). Conflict management style: Accounting for cross-national differences'. Journal of International Business Studies, 29, 729-48.

McEvily, B., Wilson, J. M. \& Straus, S. G. (2006). All in due time: the development of trust in computermediated and face-to-face teams. Organ Behav Hum Decis Process, 99(1), 16-33.

Nurmi. (2010). Coping with Coping Strategies: How Distributed Teams and Their Members Deal with the Stress of Distance, Time Zones and Culture, Department of Industrial Engineering and Management, Laboratory of Work Psychology and Leadership, Helsinki University of Technology, Finland.

Michael, A. W. (2004). Aston University, Aston Business School, Birmingham B4 7ET, UK.

Pirola-Merlo, A., Richver, A., Hirst, G., Mann, L. \& Bain, P. (2004). Learning to lead: The development and testing of a model of leadership learning. The Leadership Quarterly, 15, 311-327. 
Rahim, M. A. (2001). Managing conflict in organizations (ed.). Westport: Quorum.

Rahim, M. A., Antonioni, D. \& Psenicka, C. (2001), A structural equations model of leader power, subordinates 'styles of handling conflict, and job performance. International Journal of Conflict Management, 12(3), 191-211.

Richter, A. W., West, M. A., van Dick, R. \& Dawson, J. F. (2006). Boundary spanners' identification, intergroup contact, and effective intergroup relations. The Academy of Management Journal, 49, 1252-1269.

Rodgers, T. L., Brown, H. G. \& Scott Poole, M. (2004). Interpersonal traits, complementarily, and trust in virtual collaboration. Journal of Management Information Systems, 20(4), 115-137.

Rousseau, D. M., Sitkin, S. B., Burt, R. S. \& Camerer, C. (1998). Not so different after all: A cross discipline view of trust. Academy of Management Review, 23, 393-404.

Somech, A. \& Lidgoster, H. (2010). Innovation and conflict management in work teams: The effects of team identification and task and relationship conflict. Negotiation and Conflict Management Research, 3(1), 28-48.

Somech, A., Desivilya, H. S. \& Lidogoster, H. (2009). Team conflict management and team effectiveness: the effects of task interdependence and team identification. Journal of Organizational Behavior, 30, 359-378.

Syna, D., Somech, A. H. \& Lidogoster, H. (2009). Team conflict management and team effectiveness: the effects of task interdependence and team identification. Journal of Organizational Behavior, $30(3), 359-78$.

Tjosvold, D. (1993). Learning to manage conflict: Getting people to work together productively. New York: Lexington Books.

Tjosvold, D. (1997). Conflict within interdependence: Its value for productivity and individuality. In C. K. W. De Dreu \& E. Van de Vliert (Eds.), Using conflict in organizations (pp. 23-37). London: Sage.

Tjosvold, D. \& Law, K. S. (2000). Conflict management, efficacy, and performance in organizational teams. Personnel Psychology, 53, 625-642.

Tjosvold, D., Hui, C., Ding, D. \& Hu, J. (2003). Conflict values and team relationships: Conflict's contribution to team effectiveness and citizenship in China. Journal of Organizational Behavior, 24, 69-88.

Tjosvold. (2009). Conflict management between and within teams for trusting relationships and performance in China. Journal of Organization Behavior, 30, 41-43.

Yetton, P. W. \& Bottger, P. C. (1988). An integration of process and decision scheme explanations of group problem solving performance. Organizational Behavior and Human Decision Processes, 42, 234249. doi: 10.1016/0749-5978(88)90014-3. West, M. 2004 In: Professional Business and Technical Management. p. 25-28. 4 p. 